\title{
Discriminated avoidance conditioning: Stimulus function in shaping and training
}

GERALD B. BIEDERMAN

UNIVERSITY OF TORONTO

The avoidance performance of 180 Wistar rats improved under the CS training condition of Noise or Noise + Light, and discontinuous UCS (shock). Responding during the intertrial interval increased when light alone served as CS. Varying the $C S$ and UCS conditions of shaping trials had no effect on subsequent avoidance performance. Again a sharp decrement in level of avoidance was found compared to previous studies.

Experiments devoted to the program of determining the experimental variables controlling discriminated avoidance learning (D'Amato, Keller, \& DiCara, 1964; Biederman, D'Amato, \& Keller, 1964; D'Amato, Keller, \& Biederman, 1965) have had considerable success in obtaining a high degree of discriminated avoidance conditioning by the manipulation of the nature of the UCS (continuous or discontinuous shock) and the discriminanda (light and/or white noise).

Recently an experiment was performed in which the importance of the duration of the intertrial interval (ITI) was investigated (Biederman, 1967). This experiment reproduced the usual finding that discontinuous shock significantly enhances avoidance learning and suggested that Wistar Ss perform better at ITI $90 \mathrm{sec}$, and that Sprague-Dawley Ss perform better at ITI 22.5 sec, during shaping and training. Despite the similarity in procedure, the best experimental subgroup only produced $25.4 \%$ avoidance over the final 400 experimental trials, as opposed to conditioning rates at least three times this level in optimal experimental groups of prior studies.

The present experiment was designed to systematically manipulate the stimuli in shaping and training which normally produce high levels of avoidance. Subjects

Ss were 180 Wistar rats, experimentally naive, purchased from Canadian Research Animal Farms, Bradford, Ontario. The animals were 100 days old at the start of the experiment.

\section{Apparatus and Procedure}

The equipment for this experiment was the same as that employed in Biederman (1967), which consisted of two commercial Skinner boxes with independent automatic programming. On Day 1 Ss were shaped (as necessary) to press a lever to terminate (escape) electric shock applied via the floor grid. Forty shaping trials were given on Day 1, and an ITI of VI $45 \mathrm{sec}$ was employed. Ss were randomly assigned to one of three stimulus conditions during shaping in which the CS was the illumination of the three pilot lights over the bar, white noise, or the compound of both stimuli
(Light and Noise). The ventilating fan provided masking noise during all conditions. Ss were also assigned randomly to either of two shock conditions (continuous or discontinuous shock) which cycled 0.2 sec on, 2.0 sec off. The shock level was $1.0 \mathrm{~mA}$ for each $S$ in both shaping and training. On Day $2 \mathrm{Ss}$ were given 500 training trials, after random assignment to the three stimulus conditions and the three shock conditions during training, in an overall 3 by 2 by 3 by 2 design. A VI $45 \mathrm{sec}$ ITI was maintained. Avoidances (response during the CS interval) and escapes were automatically recorded. The avoidance percentage for each $S$ over the last 400 training trials constituted the main dependent measure. In the hopes of detecting any differences in response pattern which might clarify the decrement in avoidance obtained in Blederman (1967), the intertrial responses (ITR), which are the bar presses made in the ITI during training, were automatically recorded.

Results

The mean percentages of avoidance responses for the three CS conditions during shaping and training are presented in Fig. 1. Although the level of avoidance remains low the conditioning is consistent with that of D'Amato et al (1964). Noise, and noise + light during training produced significantly more avoidance than light alone. Analysis of variance shows the training stimulus variable was effective $(F=3.43$, df $=2 / 144$, $p<.05)$. The compound stimulus condition and the sound condition were significantly more productive of avoidance respectively than was the light condition (compound vs light, $t=2.38, d f=118, p<.02$; sound vs light, $t=2.15$, $d f=118, p<.05)$. There was no significant difference between sound and compound stimuli. The shock main effect during training was highly

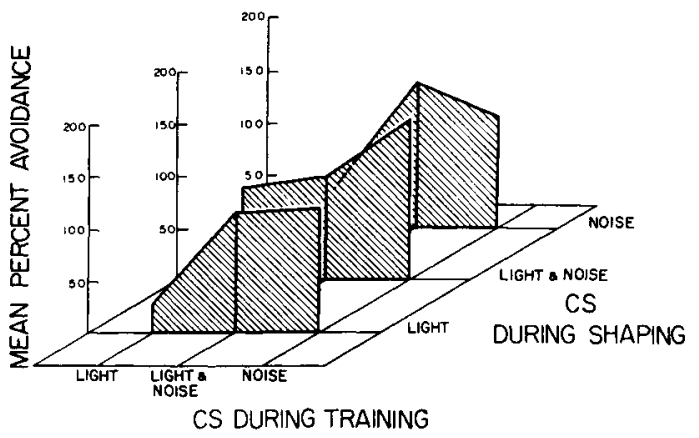

Fig. 1. Mean percentages of avoidance responding for CS conditions in shaping and training. 
significant $(F=9.71, \mathrm{df}=1 / 144, p<.005)$; the relationship between type of shock and the stimulus condition is presented in Fig. 2. No other main effect (those during shaping) nor interaction achieved significance.

Analysis of variance using ITR as the dependent measure showed that only the stimulus conditions during training were significant $(F=4.33, d f=2 / 144$, $\mathrm{p}<.05)$. The mean percentages during training and shaping are given in Fig. 3. The light stimulus condition produced significantly more ITR than the two remaining conditions (light $v$ s compound, $t=2.42, \mathrm{df}=$ $118, p<.02$; light vs sound, $t=2.66, d f=118, p<.01$ ). The difference between sound and light conditions was not significant. There was no correlation between avoidance performance and amount of ITR (product moment $r=-.002$ ).

\section{Discussion}

This study has found that the stimulus conditions during shaping are of no significant consequence in avoidance during the last 400 training trials. This is in contrast to the finding that (depending on strain) ITI during shaping influences later avoidance (Biederman, 1967). ITR was increased by the use of light CS during training; this finding is probably explained by an increase in bar-holding during this condition. The use of the compound stimulus also changed the rate of ITR to that of the sound CS, as it did with the avoidance measure.

This experiment confirms the follows findings: (a) discontinuous shock is superior to discontinuous shock in producing avoidance, (b) light is inferior to sound

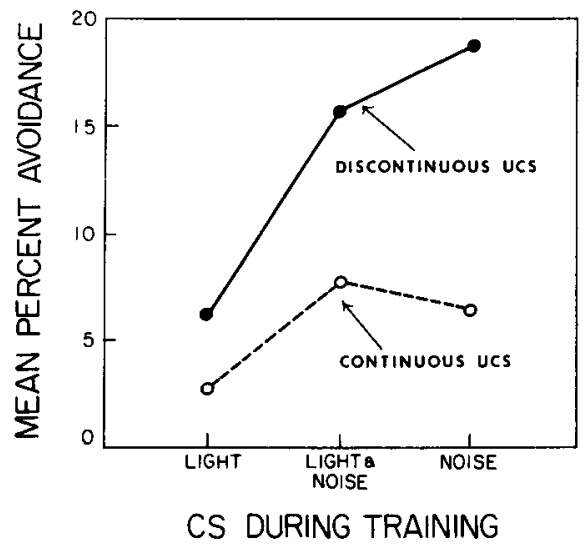

Fig. 2. Mean percentage of avoidance as a function of type of shock and CS condition during training.

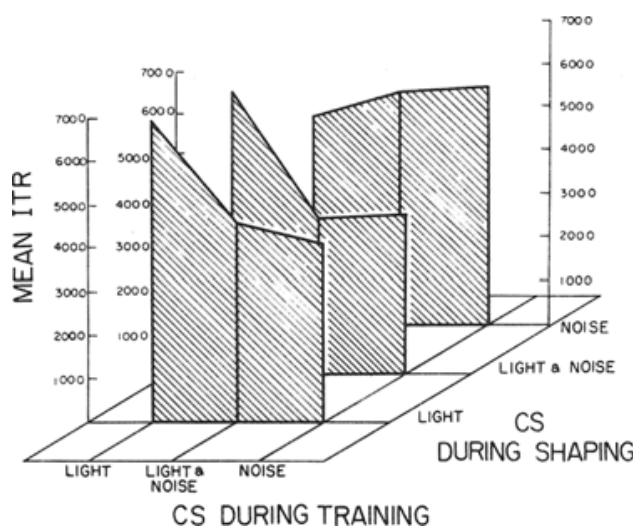

Fig. 3. Mean percentages of ITR for CS conditions during shaping and training.

CS or the compound of light + sound in avoidance learning, (c) type of shock during shaping is of no significant consequence to later learning. It is apparent that the data produced in this experiment and in Biederman (1967) are consistent with the work of D'Amato et al (1964, 1965) with respect to the CS and UCS variables producing significant improvement in avoidance conditioning. What is not at all clear is the cause of the low general level of performance of Ss in this and the preceding study. Every significant training and handling routine as well as the equipment employed are virtually identical with $D^{\prime}$ Amato et al (1964, 1965) and Biederman et al (1964). The role of S strain is probably important but cannot serve as the complete explanation since the Sprague-Dawley strain used in some of the earlier experiments was also used in Biederman (1967) without improving the overall level of avoidance.

\section{References}

BIEDERMAN, G, B. Discriminated avoidance conditioning as a function of parameters of ITI and type of shock. Psychon. Sci, 1967, 9, in press.

BIEDERMAN, G. B., D'AMATO, M. R., \& KELLER, D. M. Facilitation of discriminated avoidance learning by dissociation of CS and manipulandum. Psychon. Sci, 1964, 1, 229-230.

D'AMATO, M. R., KELLER, D., \& BIEDERMAN, G. Discriminated avoidance learning as a function of parameters of discontinuous shock. J. exp. Psychol, 1965, 70, 543-548.

D'AMATO, M. R., KELLER, D., \& DiCARA, L. Facilitation of discriminated avoidance learning by discontinuous shock. J. comp. physiol. Psychol., 1964, 58, 344349.

\section{Note}

1. This research was supported by Canadian NRC Grant APA 185. 1 thank G. Heighington and M. Archer for their assistance. 